\title{
Development of a Four Phase Floating Interleaved Boost Converter for Photovoltaic Systems
}

\author{
Christopher D. Lute, Marcelo Godoy Simões, and \\ Danilo Iglesias Brandão \\ Electrical Engineering and Computer Science \\ Colorado School of Mines \\ Golden, USA
}

\author{
Ahmed Al Durra, and S. M. Muyeen \\ Electrical Engineering \\ The Petroleum Institute \\ Abu Dhabi, UAE
}

\begin{abstract}
This paper explores the advantages of the Floating Interleaved Boost Converter, particularly with regards to solar photovoltaic power systems. This converter offers improved efficiency and voltage gain, while having lower input current ripple than other DC-DC boost converters. An analog linear feedback controller was developed, and adapted for discrete control. Two Maximum Power Point Tracking methods were explored, and their performances were evaluated in simulation. An experimental prototype was developed and demonstrated. The results show that this is a promising converter topology with many potential benefits for solar power applications.
\end{abstract}

\section{INTRODUCTION}

Renewable power generation technologies, such as solar and wind, are receiving increased interest for electricity production because they are non-polluting and do not derive from finite resources. Solar photovoltaic (PV), in particular, has found numerous applications, ranging from small, standalone systems to utility-scale, grid-connected power plants [1]. At the end of 2012, cumulative installed, grid-connected PV capacity in the US reached approximately $7.4 \mathrm{GW}$. Of the nearly $316,000 \mathrm{PV}$ installations which were connected to the grid in 2012, approximately 283,000 (nearly $90 \%$ ) were residential systems [2].

PV modules produce a low DC voltage, typically around 20-30 V [3]. However, a high input voltage is necessary for efficient conversion to alternating current when using a DC$\mathrm{AC}$ inverter. Series combination of several modules reduces reliability; a failure of any one module in a series string will result in the loss of the entire string, and total string current will be dictated by the lowest performing module in the string. In partial-shading situations, shading of a single module will diminish the power output of the entire string. Therefore, it is advantageous to combine modules in parallel and use a DC-DC converter to increase the output voltage to the required input of the DC-AC inverter.

The floating, interleaved boost converter (FIBC) has been proposed as a solution for fuel cell, electrical vehicle and PV applications due to its high voltage gain, high efficiency, and low input-current ripple [4]. Laboratory prototypes have

The authors are grateful to The Petroleum Institute, Abu Dhabi, UAE for providing the funding support for this research. been developed to demonstrate the operational principles of this converter type [4], [5], [6]. Experimental results were obtained using an emulated fuel cell power source [7], [8].

This paper will provide an analysis of the four phase (4P) FIBC. A discrete, dual-loop, linear feedback controller will be developed. Maximum Power Point Tracking (MPPT) capability will be integrated. Modeling and simulation results will be used to validate the design. Finally, the development of a hardware prototype will be described, and experimental results presented.

This work will be novel by developing a FIBC specifically for a PV application. It will use a single, fixed point, embedded microcontroller to execute all control functions.

\section{Photovoltaic Power System}

A typical PV power system block diagram is shown in Fig. 1. A PV array is connected to a DC-DC boost converter to achieve the required DC link voltage. An energy storage system (e.g., battery) connects through a bidirectional charge controller. An inverter is connected to produce AC power, with an LCL filter to limit the harmonics [9]. For gridconnected systems, this AC output would be connected to the utility grid. The inverter could be unidirectional, or bidirectional to allow grid power to charge the battery.

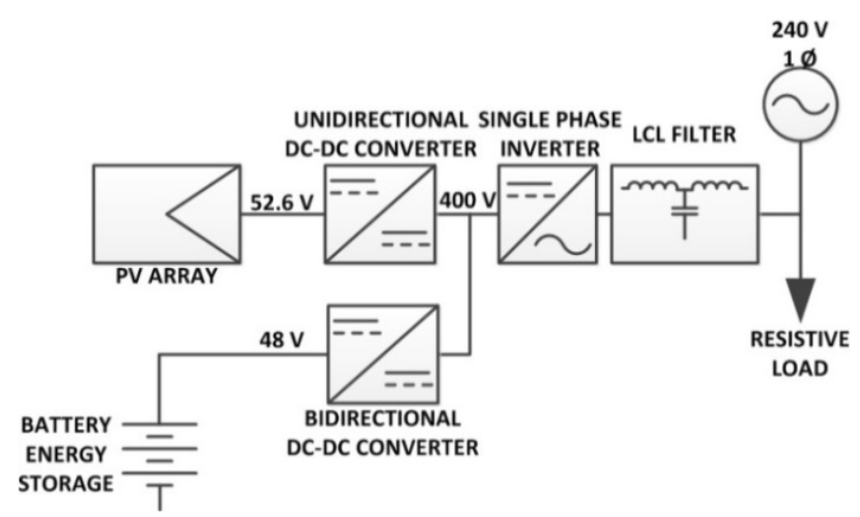

Figure 1. Typical PV power system block diagram. 
A full day simulation of this system was conducted using PSIM. One simulation second was equal to eight hours (hr) of real time. At the start, the PV was producing close to full rated output, supplying the $2 \mathrm{~kW}$ resistive load, and charging the battery. At simulation time $\left(\mathrm{t}_{\mathrm{s}}\right)=8 \mathrm{hr}$, the PV stopped producing power, and the battery supplied the $2 \mathrm{~kW}$ load. At $\mathrm{t}_{\mathrm{S}} \approx 19 \mathrm{hr}$, the battery state of charge (SOC) dropped below its minimum. At this point, the battery disconnected, and the load was supplied by the grid. The power outputs from the various sources are plotted in Fig. 2, and Fig. 3 plots the DC link voltage, and the inverter voltage and current waveforms.

\section{CONVERTER OPERATION AND ANALYSIS}

The circuit for the 4P FIBC is shown in Fig. 4. Although the FIBC requires a greater number of components than conventional converters, each component only carries a fraction of the total input current and output voltage, so that lower rated devices may be used. Increased number of phases reduces current, hence conduction losses. Staggered switching of the phases reduces input current ripple. More than four phases yields on marginal improvement [7].

First, it is assumed that in each switching period the average voltage across the inductors and the average current through the capacitors are null. In addition, in steady state the average current is assumed to be identical through each inductor, and the average voltage is equal across both capacitors. Then, the output/input voltage ratio (voltage gain) can be easily found by analyzing one of the passive elements that transfers energy from input to output.

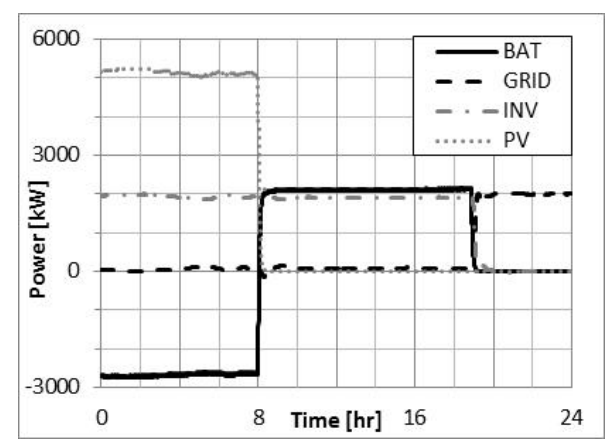

Figure 2. Power outputs for full system simulation.

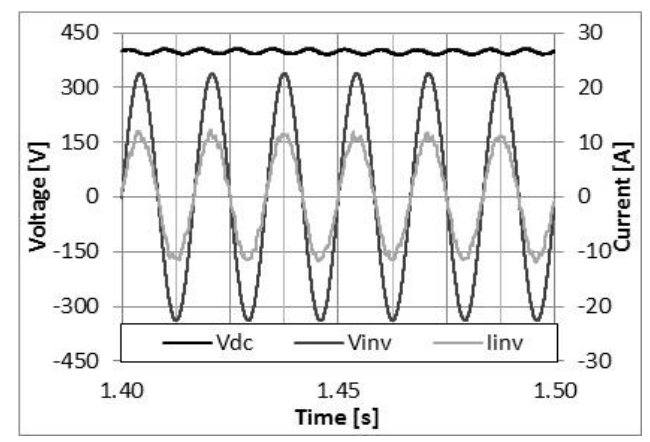

Figure 3. DC link voltage, inverter voltage and current.

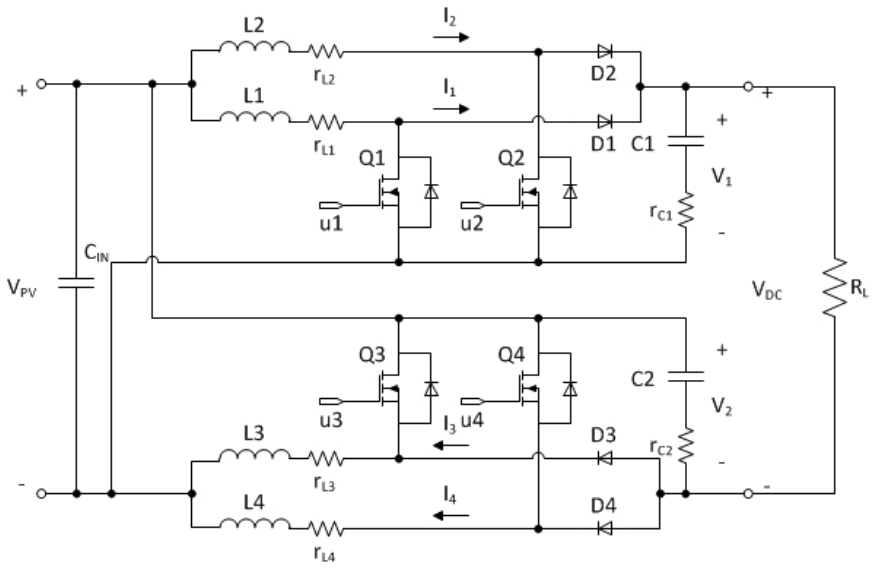

Figure 4. Circuit schematic of 4P FIBC.

Choosing the inductor $\mathrm{L}_{1}$ operating in continuous conduction mode, the following equation can be defined:

$$
V_{P V} \cdot U+(1-U) \cdot\left[V_{P V}-\frac{1}{2} \cdot\left(V_{D C}+V_{P V}\right)\right]=0
$$

where $U$ is the duty cycle of the four switches.

From this, the 4P FIBC static characteristic $[\mathrm{H}(\mathrm{u})]$ can be written as:

$$
H(u)=\frac{V_{D C}}{V_{P V}}=\frac{1+U}{1-U}
$$

This reveals one of the implicit advantages of the FIBC as compared to a conventional boost converter, whose static characteristic is:

$$
H(u)=\frac{1}{1-U}
$$

The $(1+\mathrm{U})$ expression in the numerator of the static transfer function for the 4P FIBC allows it to produce a higher output voltage for the same duty cycle than a conventional boost converter.

The FIBC is a non-linear system, although it is reasonable to consider the average values of the switched quantities, due to the huge difference between the switching frequency and the inner current control loop crossover frequency. The duty cycles of the four switches are expressed as " $u_{n}$ ", where $\mathrm{n}=1,2,3$, or 4 . Based on the previous description, Fig. 4, and Kirchhoff's voltage and current laws, the six state space linear equations for the $4 \mathrm{P}$ FIBC can be expressed by:

$$
\begin{aligned}
& L_{1} \frac{d i_{1}}{d t}=V_{P V}-\left(1-u_{1}\right) v_{1} \\
& L_{2} \frac{d i_{2}}{d t}=V_{P V}-\left(1-u_{2}\right) v_{1} \\
& L_{3} \frac{d i_{3}}{d t}=V_{P V}-\left(1-u_{3}\right) v_{2} \\
& L_{4} \frac{d i_{4}}{d t}=V_{P V}-\left(1-u_{4}\right) v_{2}
\end{aligned}
$$




$$
\begin{aligned}
& C_{1} \frac{d v_{1}}{d t}=\left(1-u_{1}\right) i_{1}+\left(1-u_{2}\right) i_{2}-\frac{v_{D C}}{R_{L}} \\
& C_{2} \frac{d v_{2}}{d t}=\left(1-u_{3}\right) i_{3}+\left(1-u_{4}\right) i_{4}-\frac{v_{D C}}{R_{L}}
\end{aligned}
$$

To design the converter's control loops (current and voltage), the transfer functions between the inductor current $\left(i_{L}\right)$ and duty cycle $(u)$ and between the DC link voltage $\left(v_{l, 2}\right)$ and duty cycle are required.

Based on (1) and (2) the desired transfer functions may be found, such that $U^{\prime}$ is the duty cycle complement (1-U) [10].

$$
\begin{gathered}
G_{i}(s)=\frac{i_{L}(s)}{u(s)}=K_{i} \cdot \frac{\left(1+\frac{s}{w_{z i}}\right)}{\left(1+\frac{s}{w_{0} Q}+\frac{s^{2}}{w_{0}^{2}}\right)} ; \\
G_{v}(s)=\frac{v_{1,2}(s)}{u(s)}=K_{v} \cdot \frac{\left(1-\frac{s}{w_{z r}}\right) \cdot\left(1+\frac{s}{w_{z l}}\right)}{\left(1+\frac{s}{w_{0} \ell}+\frac{s^{2}}{w_{0}^{2}}\right)},
\end{gathered}
$$

where:

$$
\begin{gathered}
w_{0}=\frac{1}{\sqrt{L C}} \cdot \sqrt{\frac{2 R U^{\prime 2}+2 R_{L}}{R+2 R_{C}}} ; \\
Q=\frac{w_{0} \cdot\left(R+2 R_{C}\right) \cdot L C}{R C \cdot\left(R_{L}+2 R_{C} U^{\prime 2}\right)+2 \cdot\left(L+R_{C} R_{L} C\right)} ; \\
K_{i}=\frac{V_{P V} \cdot(3+U)}{2 U^{\prime} \cdot\left(R U^{\prime 2}+R_{L}\right)} ; \\
K_{v}=\frac{1}{2} \cdot \frac{V_{P V} \cdot\left[2 R U^{\prime 2}-R_{L} \cdot(1+U)\right]}{U^{\prime 2} \cdot\left(R U^{\prime 2}+R_{L}\right)} ; \\
w_{z i}=\frac{(3+U)}{R C+C R_{C} \cdot(3+U)} ; \\
w_{z r}=\frac{2 R U^{\prime 2}-R_{L} \cdot(1+U)}{L \cdot(1+U)} ; \\
w_{z l}=\frac{1}{C R_{C}}
\end{gathered}
$$

\section{MAXIMUM POWER POINT TRACKING}

Solar PV modules have a non-linear voltage versus current relationship. For part of their operational range, PV modules are approximately current sources, while for the other portion of their range they operate as voltage sources. The result of this is that there exists one point along the voltage/current curve for which the power produced by the PV device is at its maximum. This is illustrated in Fig. 5. The location of the Maximum Power Point (MPP) varies under varying irradiance and temperature conditions.

Due to the relatively low conversion efficiency and high cost of PV technology, extracting the maximum useful power is an important design criterion for PV power systems. Therefore, a number of techniques have been developed in order to operate PV systems at their MPP [11]. These techniques are known collectively as MPPT. In this paper, two different conventional MPPT techniques are presented. These were applied to the 4P FIBC. The performance of the converter under different irradiance and temperature conditions was quantified and compared.

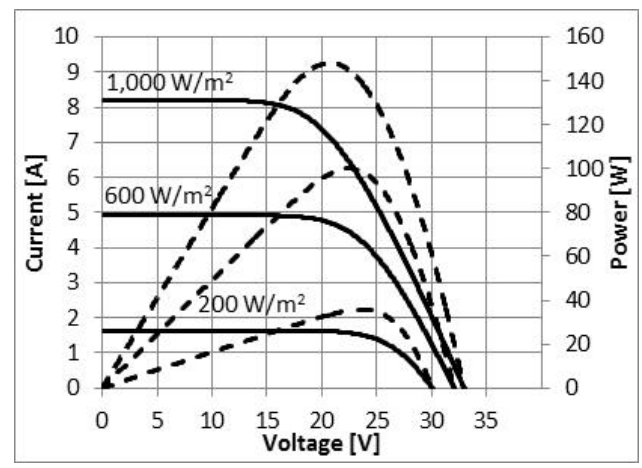

Figure 5. Generalized voltage vs. current relationship for a PV module.

Many different MPPT algorithms have been developed and used. One of these, the Perturb and Observe (P\&O) method, works by inducing small changes in the operating voltage or current of the PV module and determining whether the power increases or decreases. If the induced change increases the power output, the operating conditions will be incremented in the same direction. If the power decreases, the increments will be reversed. This method suffers from a tendency to oscillate around the MPP, and can be ineffective under rapidly changing atmospheric conditions [12].

The Incremental Conductance (IC) method attempts remedy these shortcomings [12]. It works based on the fact that the derivative of the PV power with respect to its voltage is zero at the MPP. This derivative can be expressed by [13]:

$$
\frac{d P}{d V}=\frac{d(I V)}{d V}=I+V \frac{d I}{d V} \cong I+V \frac{\Delta I}{\Delta V}
$$

From this, it can be determined that:

$$
\left\{\begin{array}{c}
\Delta I / \Delta V+I / V=0 \text { at } M P P \\
\Delta I / \Delta V+I / V>0 \text { left of } M P P \\
\Delta I / \Delta V+I / V<0 \text { right of } M P P
\end{array}\right.
$$

Using these inequalities, the MPP can be achieved. Additionally, the IC technique indicates both the direction and distance of the operating condition from the MPP. A modification to this technique uses a feedback control loop to drive $\Delta \mathrm{I} / \Delta \mathrm{V}+\mathrm{I} / \mathrm{V}$ to zero [12]. The main disadvantage for the IC algorithm is that it requires greater computational resources when using an embedded controller due to the multiple division operations involved.

\section{CONTROL DESIGN}

The control loops must ensure the system stability and damp the switching frequency. The controllers were designed for the 4P FIBC using the Bode diagram frequency analysis. Proportional-integral (PI) controllers were used for the current and voltage control. The controller gains were defined by the crossover frequency $\left(f_{c}\right)$ and phase margin 
(PM), such that the infinite gain was related to zero steadystate error, and the crossover frequency was related to the setting time of the compensated system.

\section{A. Analog Controller}

The analog controller used two outer voltage control loops that independently regulated the two output capacitor voltages to achieve the desired output level. This used the fact that the output DC link voltage of the FIBC is the series combination of the two capacitor voltage, minus the input (PV) voltage, or:

$$
V_{D C}=V_{c 1}+V_{c 2}-V_{P V}
$$

The reference value for the two capacitors can be expressed as a function of the desired output voltage and input voltage by:

$$
\mathrm{V}_{\mathrm{c} 1,2}{ }^{*}=\left(\mathrm{V}_{\mathrm{DC}}{ }^{*}-\mathrm{V}_{\mathrm{PV}}\right) / 2
$$

This approach differed from the dual loop controller used by Kabalo, et al., in [8], in which the outer loop controller regulated the total DC link voltage. Garcia, et al., in [5] used a similar strategy in which both output capacitor voltages were controlled independently. For this application, controlling the capacitors individually was found to yield better performance, particularly in low irradiance conditions. This is due to the voltage-current response of the PV.

Past a certain point, increasing the duty cycle causes the PV to enter its current source region, decreasing the input voltage to the converter. The decreased input voltage leads to decreased output voltage.

If only the output voltage is controlled, overshoot in the controller will cause the voltage to cross the knee point of the curve and decrease. The controller will attempt to compensate by increasing the duty cycle, which will cause the output to go even lower, until the controller eventually saturates. In contrast, by controlling the capacitor voltages, the reference is dependent on the magnitude of the input voltage, as shown in Eq. 15. Therefore, the input voltage acts as a feed-forward term, making the controller more robust and allowing faster crossover frequency.

The benefits of this strategy are most apparent in low irradiance conditions, where the knee point of the voltage curve occurs at a lower value of input current. This is illustrated in Fig. 6, in which the irradiance steps from 200 to $300 \mathrm{~W} / \mathrm{m}^{2}$ at time $\mathrm{t}=1 \mathrm{~s}$.

The capacitor voltage $\left(\mathrm{V}_{\mathrm{c}}\right)$ control scheme showed a much more stable response. The DC link voltage $\left(\mathrm{V}_{\mathrm{dc}}\right)$ control scheme showed steady state stability problems, and failed to converge following the step irradiance change.

The output from the voltage controller $\left[\mathrm{C}_{\mathrm{v}}(\mathrm{s})\right]$ then fed four, independent, PI current controllers $\left[\mathrm{C}_{\mathrm{i}}(\mathrm{s})\right]$ that regulated the four inductor currents. An additional term from the MPPT was added to this current reference. The outputs from the current control loops were then used as the modulation signals for four Pulse Width Modulation (PWM) controllers, which provided the gate pulse signals for the four MOSFET switches independently. The PWM controllers used $20 \mathrm{kHz}$ switching frequency, with the four switching signals phase shifted $90^{\circ}$ apart.

The control scheme topology is illustrated in Fig. 7. A dual loop controller was used. A faster, inner current control loop integrated the MPPT functions. An outer voltage control loop maintained the desired DC link voltage. The control design was conducted using the Bode diagram method for classical frequency control.

\section{a) Current control loop:}

The inner current control loop was designed first. The $f_{c}$ and PM were defined as $1.5 \mathrm{kHz}$ and $75^{\circ}$, respectively. The Bode diagram of the open loop, uncompensated and compensated systems is shown in Fig. 8.

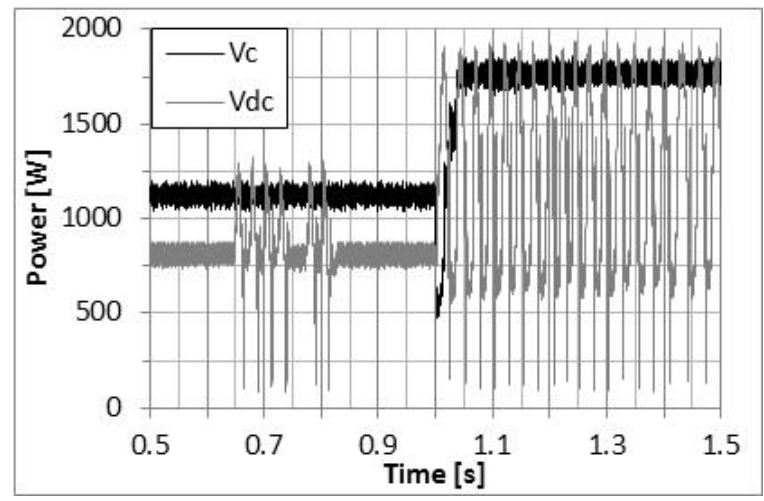

Fig. 6. Power response for $V_{c}$ and $V_{d c}$ voltage control strategies for a step change in irradiance from 200 to $300 \mathrm{~W} / \mathrm{m}^{2}$ at time $\mathrm{t}=1 \mathrm{~s}$.

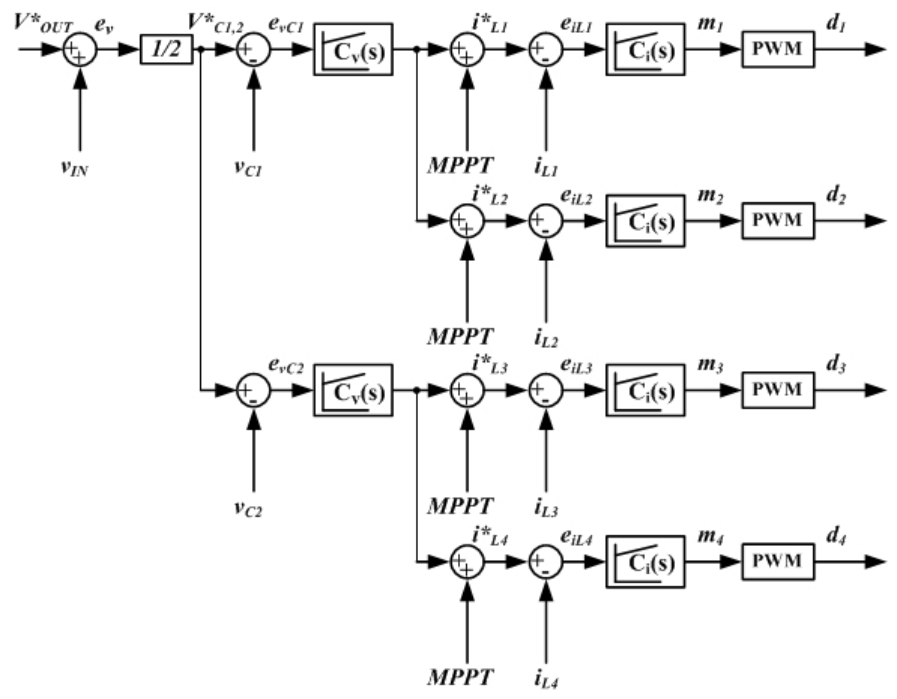

Figure 7. Control block diagram for 4P FIBC. 


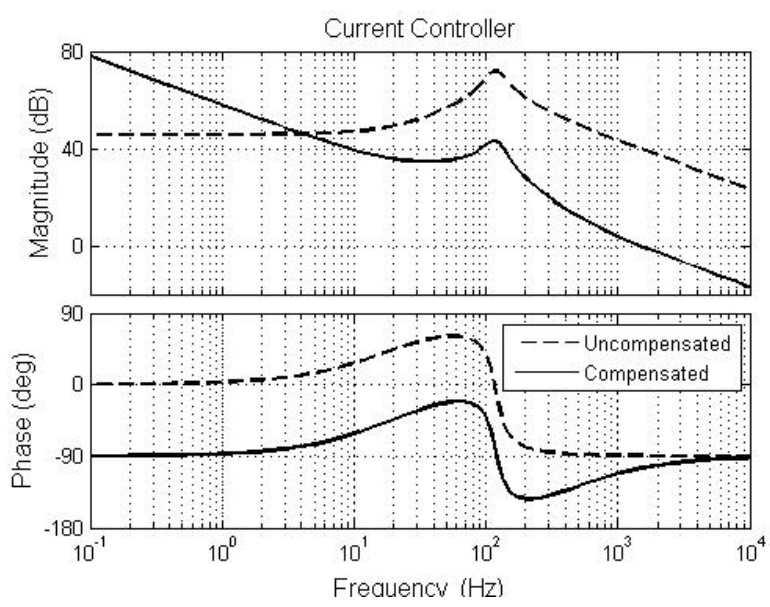

Figure 8. Bode diagram of the open loop uncompensated and compensated current control loop of the FIBC control scheme.

Using classical frequency method, the following controller can be designed. The Bode diagram of the open loop, compensated system in Fig. 8 confirmed that $f_{c}=1.5$ $\mathrm{kHz}$ and $\mathrm{PM}=75^{\circ}$.

$$
C_{i}(s)=\frac{(0.01 s+25)}{s}
$$

\section{b) Voltage control loop:}

After the current controller, the voltage control loop was designed, which depended on the inner current control loop. The desirable $f_{c}$ and $\mathrm{PM}$ were designed to be $5 \mathrm{~Hz}$ and $85^{\circ}$, respectively. The voltage control loop must be significantly slower to avoid steady state current oscillation.

The PI controller has been designed based on these values for $f_{c}$ and $\mathrm{PM}$, and the Bode diagram of the open loop, uncompensated and compensated systems is shown in Fig. 9.

$$
C_{v}(s)=\frac{(0.04 s+7)}{s}
$$

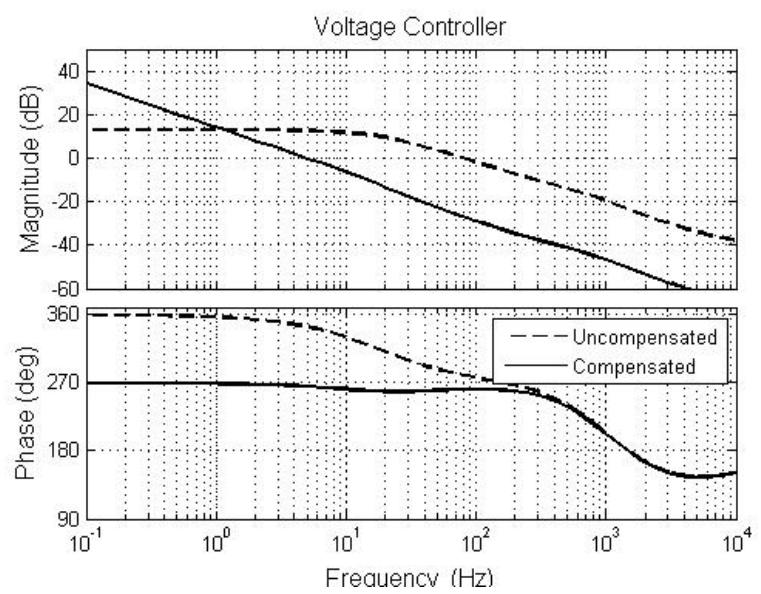

Figure 9. Bode diagram of the open loop uncompensated and compensated voltage control loop of the FIBC control scheme.

\section{B. Discrete Controller}

A discrete controller was developed using the previously developed analog controller. For the discrete controller, the analog PWM had to be replaced with a discrete PWM. The PI controllers were replaced with discrete versions that used the Tustin approximation for the integration.

In order to obtain a working controller while only updating the state feedback values once per cycle, the samples were synchronized. As the ripple in the inductor currents was equal to the switching frequency, the average value occurs during the middle of the switch on or off period. By timing the sample to occur during this time, the average value of the state variable could be obtained. This allowed the current control loops to function without requiring low pass filtering to obtain the signal's average value [14].

The voltages, which were subject to higher frequency ripple than the currents, were filtered through a low pass filter with a $50 \mathrm{kHz}$ cut-off frequency prior to sampling. By employing these strategies, all feedback variables could be sampled only once per switching cycle, thereby minimizing the computational burden.

\section{SimULATION RESUlTS}

Matlab and Simulink software packages were used to develop both the analog and digital controllers. After being developed, the analog controller was then implemented using PSIM software, and validated against the Simulink results. The discrete controller was simulated in C code using the $\mathrm{C}$ block available in PSIM.

Two MPPT methods, the P\&O and IC techniques, were implemented using the analog controller: Their performance was evaluated in response to step changes in solar irradiance at various temperatures. The controllers were evaluated according to the total energy delivered to a resistive load, and the input current and voltage ripple.

The output of each MPPT algorithm was added to the inductor current reference from the voltage control loops. An increment/decrement interval $(\Delta)$ of $0.2 \mathrm{~mA}$ was used.

Both MPPT algorithms were tested with two step changes in irradiance: 1) $1,000 \mathrm{~W} / \mathrm{m}^{2}$ to $500 \mathrm{~W} / \mathrm{m}^{2}$, and 2) $500 \mathrm{~W} / \mathrm{m}^{2}$ to $600 \mathrm{~W} / \mathrm{m}^{2}$. These two step changes were conducted at three different temperatures: 1) $10^{\circ} \mathrm{C}$, 2) $25^{\circ} \mathrm{C}$, and 3) $40^{\circ}$ C. Thus, a total of six simulations were conducted for each algorithm.

After conducting the simulations using the analog controller, the $\mathrm{P} \& \mathrm{O}$ and IC algorithms were also evaluated using the discrete controller, using the same six simulation scenarios.

All the simulations were conducted using PSIM with a fixed simulation time step of $0.5 \mu \mathrm{s}$. The input to the $4 \mathrm{P}$ FIBC was a mathematical model of a PV array based on 26 
Kyocera KC200GT PV modules in a 2 series/13 parallel configuration. This PV module was selected because it has been well characterized and accurate models have been developed by Villalva, et al., in [15].

The output was a resistive load; the magnitude of the load resistance had to be varied in accordance with the power produced by the PV array, so that a constant voltage could be maintained under varying irradiance conditions. For the three irradiance conditions - $1,000,600$, and $500 \mathrm{~W} / \mathrm{m}^{2}$ - the resistor values used were 27,45 and $54 \Omega$, respectively.

The step change in the PV power output in response to a step decrease in solar irradiance from $1,000 \mathrm{~W} / \mathrm{m}^{2}$ to 500 $\mathrm{W} / \mathrm{m}^{2}$ for the P\&O method is shown in Fig. 10. The response for the IC was nearly identical and has been omitted.

When used with the analog controller, the P\&O and IC techniques had virtually indistinguishable performance. Both delivered nearly identical amounts of energy to the load, and both were able to operate with very little ripple. Input voltage and current ripple was calculated to be less than $1 \%$ for both MPPT algorithms. Next, the P\&O and IC algorithms were evaluated using the discrete controller.

One issue that was encountered with the discrete controller implementation was that the voltage control loop tended to overshoot, driving the inductor current reference too high, and causing the system to saturate at the PV array's short circuit current. This was particularly evident under low solar irradiance conditions. To compensate, the gain values for the voltage control loop were reduced. A reset for the integral term was introduced; when the PV voltage was detected to drop below a certain threshold (e.g., $20 \mathrm{~V}$ ), the integral term of the voltage control loop was reset to zero.

In order to increase the convergence time while avoiding overshoot, an adaptive MPPT method was developed. Rather than a fixed $\Delta$, it was scaled according to the output voltage error. The $\Delta$ was set to equal $5 * 10^{-6} *\left(\mathrm{~V}_{\mathrm{DC}}{ }^{*}-\mathrm{V}_{\mathrm{DC}}\right)$. In this way, the MPPT converged quickly but avoided overshoot. Fig. 11 shows the PV power responses for a fixed versus a variable $\Delta$ using the discrete IC controller with a step change in irradiance from $1,000 \mathrm{~W} / \mathrm{m}^{2}$ to $500 \mathrm{~W} / \mathrm{m}^{2}$ at $25^{\circ} \mathrm{C}$. It shows that the variable delta was able to converge much more quickly following the change in irradiance. This technique, however, is only valid when only the PV boost converter is controlling the DC link voltage. If another device is regulating this voltage (e.g., an inverter or other DC converter) then this technique will no longer work, and a fixed $\Delta$ must be used.

The PV power for the discrete P\&O and IC MPPT controllers in response to a step change in irradiance from $1,000 \mathrm{~W} / \mathrm{m}^{2}$ to $500 \mathrm{~W} / \mathrm{m}^{2}$ at $25^{\circ} \mathrm{C}$ is plotted in Fig. 12 . In the discrete implementation, the $\mathrm{P} \& \mathrm{O}$ technique had more observable ripple and tended to oscillate. The IC method, in contrast, was much smoother and more stable.
The energy delivered to the load, in Joules $(\mathrm{J})$, for the analog and discrete versions of the two MPPT methods is listed in Table 1. While in the analog mode, input current ripple was very low $(<1 \%)$ the discrete $\mathrm{P} \& \mathrm{O}$ and IC methods had input current ripple values of $6.36 \%$ and $2.90 \%$, respectively. This increased ripple resulted in lower energy capture, as the ripple causes the PV to deviate from its MPP. Overall, the discrete P\&O delivered on average $11.84 \%$ less energy than the analog P\&O. The discrete IC had much better performance, yielding on average just $1.69 \%$ lower energy capture than in the analog case.

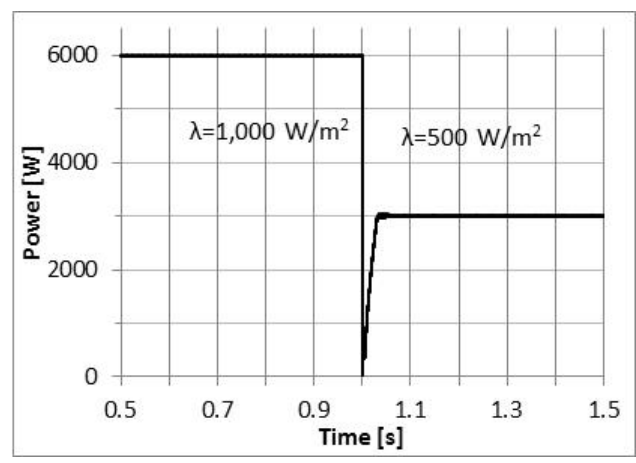

Figure 10. PV output power for analog P\&O MPPT method for a step change in irradiance from 1,000 to $500 \mathrm{~W} / \mathrm{m}^{2}$ at $\mathrm{t}=1 \mathrm{~s}$.

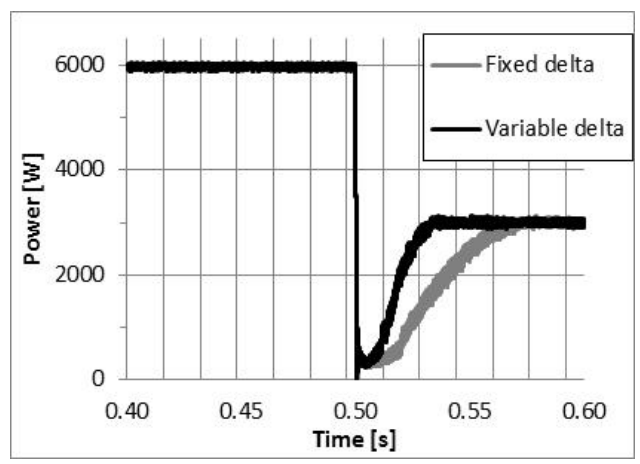

Figure 11. Fixed versus variable delta for IC MPPT, with step change in irradiance from 1,000 to $500 \mathrm{~W} / \mathrm{m}^{2}$ at $\mathrm{t}=0.5 \mathrm{~s}$.

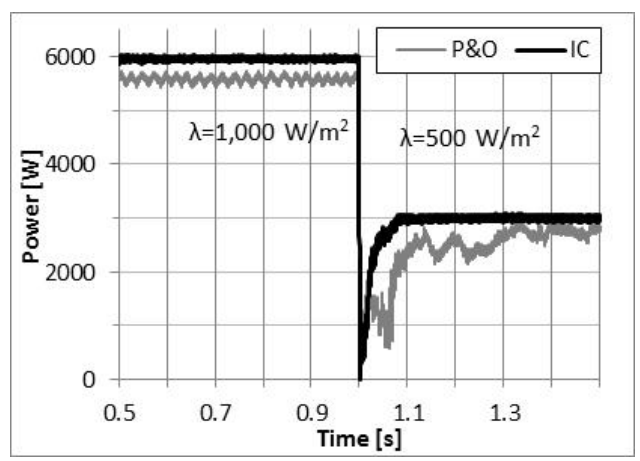

Figure 12. PV output power for discrete $\mathrm{P} \& \mathrm{O}$ and IC MPPT methods for a step change in irradiance from 1,000 to $500 \mathrm{~W} / \mathrm{m}^{2}$ at $\mathrm{t}=1 \mathrm{~s}$. 
TABLE 1. MPPT SimUlation ENERGy RESUlts AND COMPARISON

\begin{tabular}{|c|c|c|c|c|c|c|}
\hline & \multicolumn{2}{|c|}{$\mathbf{T = 1 \mathbf { 1 0 } ^ { \mathbf { 0 } } \mathbf { C }}$} & \multicolumn{2}{c|}{$\mathbf{T}=\mathbf{2 0}^{\mathbf{0}} \mathbf{C}$} \\
\hline Technique & $\begin{array}{c}\text { Step } \\
\text { decrease }\end{array}$ & $\begin{array}{c}\text { Step } \\
\text { increase }\end{array}$ & $\begin{array}{c}\text { Step } \\
\text { decrease }\end{array}$ & $\begin{array}{c}\text { Step } \\
\text { increase }\end{array}$ & $\begin{array}{c}\text { Step } \\
\text { decrease }\end{array}$ & $\begin{array}{c}\text { Step } \\
\text { increase }\end{array}$ \\
\hline \multicolumn{7}{|c|}{ Analog } \\
\hline P\&O & 4,514 & 3,312 & 4,287 & 3,151 & 4,058 & 2,988 \\
\hline IC & 4,514 & 3,312 & 4,287 & 3,151 & 4,056 & 2,988 \\
\hline P\&O & 3,718 & 2,762 & 3,789 & 2,940 & 3,694 & 2,703 \\
\hline IC & 4,358 & 3,159 & 4,250 & 3,132 & 4,013 & 3,001 \\
\hline \multicolumn{7}{|c|}{ Percentage Difference } \\
\hline P\&O & $-17.63 \%$ & $-16.61 \%$ & $-11.62 \%$ & $-6.70 \%$ & $-8.97 \%$ & $-9.54 \%$ \\
\hline IC & $-3.46 \%$ & $-4.62 \%$ & $-0.86 \%$ & $-0.60 \%$ & $-1.06 \%$ & $+0.44 \%$ \\
\hline
\end{tabular}

\section{EXPERIMENTAL RESULTS}

A 4P FIBC hardware prototype was constructed that used a Microchip dsPIC33FJ256GP170A embedded microcontroller to execute control functions. The experimental setup is shown in Fig. 13.

Testing was conducted under low power, low voltage conditions due to the limited input current and dissipative load capacity available. A 15 A DC power supply acted as the primary source. As no PV was available, MPPT testing was conducted by placing a series resistance in between the source and the FIBC prototype. Based on Thevenin's theorem, which states that for a source with a series impedance connected to a load, the maximum power transfer to the load occurs when the source resistance $\left(R_{S}\right)$ is equal to the load resistance $\left(\mathrm{R}_{\mathrm{L}}\right)$. The FIBC causes the load resistance to be reflected to the input $\left(\mathrm{R}_{\mathrm{IN}}\right)$ as:

$$
R_{I N}=R_{L} \frac{(1-D)^{2}}{(1+D)^{2}}
$$

Fig. 14 shows the steady state current results for two of the four inductor currents, contrasted with the input current. Note that while the inductor currents have the characteristic triangle wave shape typical of conventional boost converters, the overall input current is much more linear. This highlights the reduced input current ripple of the FIBC.

Fig. 15 shows the response in the input power when varying the series source resistance from $2 \Omega$ to $3 \Omega$, which reduced the theoretical maximum power from $200 \mathrm{~W}$ to $133.3 \mathrm{~W}$. The IC MPPT algorithm was able to track this change, but did not converge to the true MPP. This result was expected from simulation, however. Fig. 16 shows the input power for a sweep in duty cycle from $0-1$ for the mathematical PV array model operating at about half power. This reveals a peak of approximately $3,000 \mathrm{~W}$ for a duty cycle of 0.74 . Also shown is the same result, with the PV array replaced with a DC source and series resistance, as was used for the experimental testing. The same IC MPPT algorithm was implemented for these two sources. When using the simulated PV input, the IC algorithm was able to converge to the MPP, but for the DC source this was not the case. Therefore, testing the IC MPPT algorithm in this method is only sufficient to evaluate the general

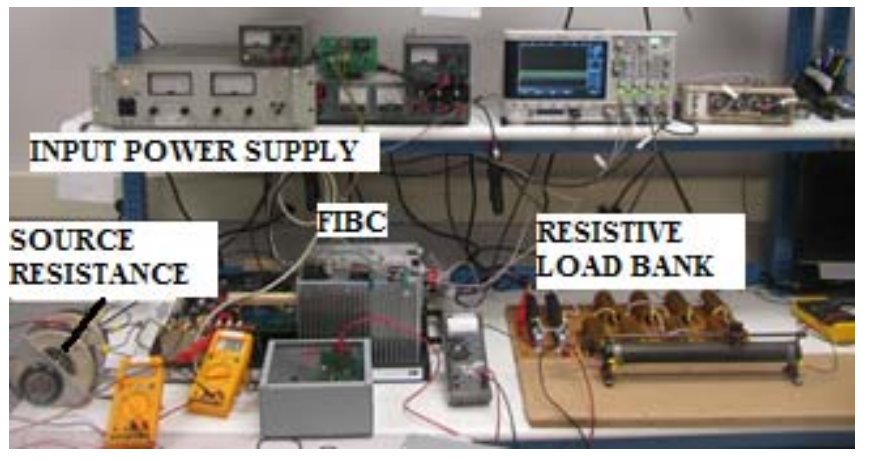

Figure 13. Experimental test setup.

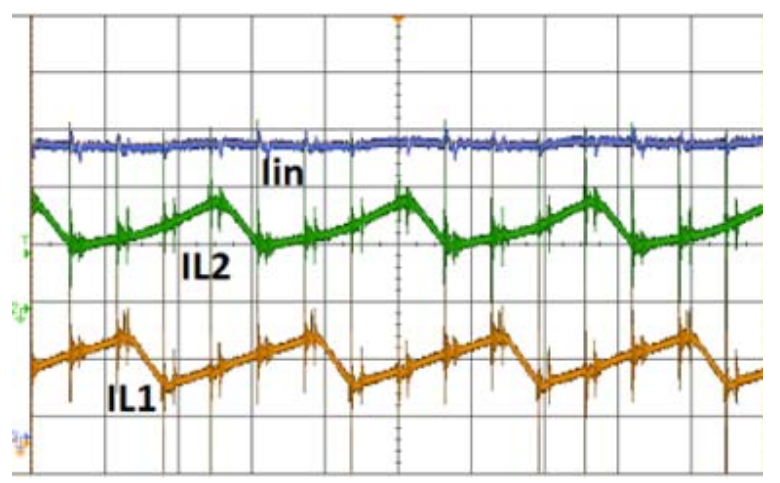

Figure 14. Inductor currents $\mathrm{I}_{\mathrm{L} 1}$ and $\mathrm{I}_{\mathrm{L} 2}$ and input current $\mathrm{I}_{\mathrm{IN}}$, steady state, 3 A reference, $2 \mathrm{~A} /$ division, $20 \mu \mathrm{s} /$ division.

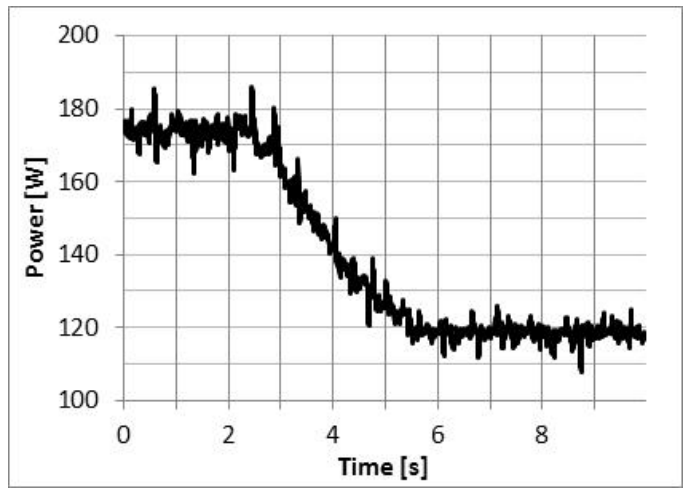

Figure 15. IC MPPT results in response to a change in source resistance from $2 \Omega$ to $3 \Omega$. 


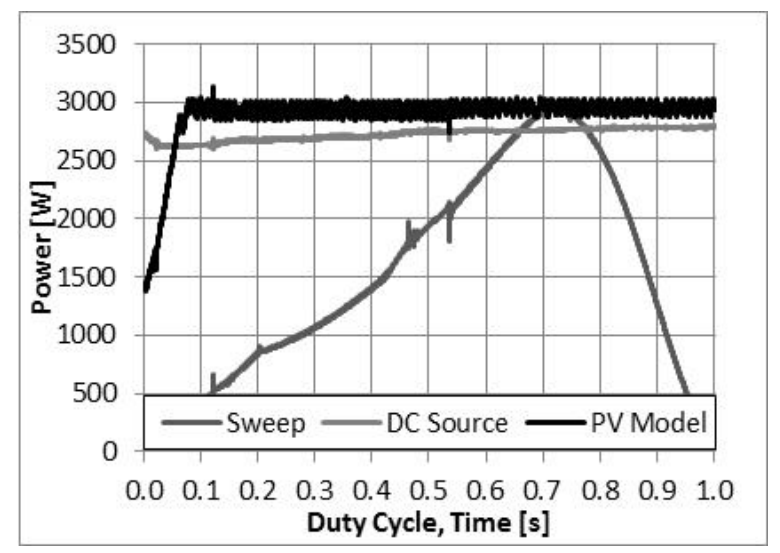

Figure 16. Simulation results for input power with duty cycle sweep compared to MPPT results for DC source with series resistance and PV model.

functionality of the IC MPPT, but it is not expected to yield the true MPP. For this, testing with a real or simulated PV input is required.

\section{CONCLUSION}

This paper identified the FIBC as a promising DC-DC converter for use in PV power applications. The FIBC offers increased voltage gain and efficiency, with lower input ripple, compared to other non-isolated DC-DC converter topologies.

Analog and discrete linear feedback controllers were developed for a 4P FIBC using Matlab/Simulink. After being developed and validated, the converter was simulated using PSIM. The discrete controller was simulated by means of C code in PSIM using the built-in C code block.

A dual loop PI controller regulated both the inductor currents and capacitor voltages of the 4P FIBC. Regulating the two capacitors individually was found to provide better performance under low irradiance conditions.

Two MPPT algorithms were introduced and evaluated, in simulation, using the analog and discrete controllers. The performance of the analog $\mathrm{P} \& \mathrm{O}$ and IC algorithms was found to be nearly identical. Both the P\&O and IC delivered less energy when discretized, and suffered from increased ripple and longer convergence times. Overall, the discrete IC performed better than the discrete $\mathrm{P} \& \mathrm{O}$ method.

The FIBC converter has numerous operational advantages that make it attractive for solar power applications.

\section{ACKNOWLEDGEMENTS}

The authors would like to gratefully acknowledge the financial support of The Petroleum Institute of Abu Dhabi for funding this research. Thanks are also due to Robert V. White, of Embedded Power Labs, for his support and design review for the hardware prototype. Magnetics Inc. provided the cores and bobbins for the inductors, and Badger
Magnetics performed the manufacturing services. Advanced Circuits manufactured the PCB.

\section{REFERENCES}

[1] K. Bolcar, and K. Ardani, "International Energy Agency Co-operative Programme on Photovoltaic Power Systems: Task 1 Exchange and dissemination of information on PV power systems", National Survey Report of PV Power Applications in the Unites States, May 2011.

[2] L. Sherwood, "U.S. Solar Market Trends 2012” Interstate Renewable Energy Council (IREC), Jul. 2013.

[3] R. Messenger and J. Ventre, Photovoltaic Systems Engineering, 2nd ed. Boca Raton, FL: CRC Press, 2004.

[4] S. Choi, V.G. Agelidis, J. Yang, D. Coutellier, and P. Marabeas, "Analysis, design and experimental results of a floating-output interleaved input boost-derived DC-DC high-gain transformer-less converter," IET Power Electron., vol. 4, iss. 1, pp. 168-180, Jan. 2011.

[5] F.S. Garcia, J.A. Pomilio, and G.Spiazzi, "Modeling an Control Design of the Interleaved Double Dual Boost Converter," IEEE Trans. Ind. Electron. vol. 60, no. 8, Aug. 2013.

[6] D. Coutellier, et al., "Experimental verification of floating-output interleaved-input DC-DC high-gain transformer-less converter topologies," Proc. IEEE PESC, 2008, pp. 562-568.

[7] M. Kabalo, et al., "Experimental validation of high-voltage ratio lowinput-current-ripple converters for hybrid fuel cell supercapacitor systems," IEEE Trans. Veh. Techno., vol. 61, no. 8, Oct. 2012.

[8] M. Kabalo, B. Blunier, D. Bouquain, M.G. Simoes, and A. Miraoui, "Advanced hybrid dual loop control for muti-phases interleaved floating DC-DC converter for fuel cell applications," Industry Applications Society Annual Meeting (IAS), 2012 IEEE, vol., no., pp. 1,8, 7-11 Oct. 2012 .

[9] A. Reznik, M.G. Simoes, A. Al-Durra, and S.M. Muyeen, "LCL Filter Design and Performance Analysis for Grid Interconnected Systems," IEEE Trans. Ind. Appl., vol. PP, no. 99, pp.1-7.

[10] M. Kabalo, et al., "Experimental evaluation of four-phase floating interleaved boost converter design and control for fuel cell applications," IET Power Electron., vol. 6, no. 2, pp. 215-226, Feb. 2013.

[11] R. Faranda and S. Leva, "Energy comparison of MPPT techniques for PV Systems," WSEAS Transactions on Power Systems, vol. 3, no. 6, pp. 446-455 Jun. 2008.

[12] T. Esram and P. L. Chapman, "Comparison of Photovoltaic Array Maximum Power Point Tracking Techniques," IEEE Trans. Energy Conversion, vol. 22, no. 2, pp. 439-448, Jun. 2007.

[13] K.H. Hussein, I. Muta, T. Hoshino, and M. Osakada, "Maximum photovoltaic power tracking: an algorithm for rapidly changing atmospheric conditions," IEE Proc.-Gener. Trasm. Distrib., vol. 142., no. 1, pp 59-64, Jan. 1995.

[14] S. Buso and P. Mattavelli, Digital Control in Power Electronics, Morgan \& Claypool, 2006.

[15] M.G. Villalva, J.R. Gazoli, and E.R. Filho "Comprehensive Approach to Modeling and Simulation of Photovoltaic Arrays," IEEE Trans. Power Electron., vol. 24, no. 5, pp. 1198-1208, May 2009.

[16] H. Sira-Ramírez and R. Silva-Ortigoza, Control Design Techniques in Power Electronics Devices, London, England, Springer, 2006.

[17] M.A.G. de Brito, L. Galotto, L.P. Sampaio, G.A. Melo, and C.A. Canesin "Evaluation of the Main MPPT Techniques for Photovoltaic Applications," IEEE Trans. Ind. Electron., vol. 60, no. 3, pp. 11561167, Mar. 2013.

[18] C. Lute, et al., "Experimental Evaluation of an Interleaved Boost Topology Optimized for Peak Power Tracking Control," presented at IEEE Industrial Electronics IECON 2014, Houston, TX, 2014. 